\title{
Paving the way for universal family planning coverage in Ethiopia: an analysis of wealth related inequality
}

\author{
Muluneh Yigzaw ${ }^{1 *}$, David Zakus², Yehualashet Tadesse ${ }^{3}$, Muluked Desalegn $^{4}$ and Mesganaw Fantahun ${ }^{5}$
}

\begin{abstract}
Background: Family planning plays a significant role in reducing maternal and child mortality and ultimately in achieving national and international development goals. It also has an important role in reducing new pediatric HIV infections by preventing unwanted pregnancies among HIV positive women. Investing in family planning is one of the smart investments for development as population dynamics have a fundamental influence on the pillars of sustainable development, including that of a sustainable environment.
\end{abstract}

Objective: To identify and quantify wealth related differences in family planning use between poor and rich Ethiopian women based on the Demographic and Health Survey asset based wealth quintiles.

Methods: The proportion of women who used contraceptives during implementation of the 2011 and 2005 Ethiopia Demographic and Health Surveys was calculated across wealth quintiles. Data were stratified for place of residence to analyze and determine inequalities in family planning use separately for rural and urban women. Socioeconomic inequalities according to wealth were measured using the slope index of inequality and the relative index of inequality.

Result: The absolute difference of contraceptive prevalence between poorest and richest women was over 25.3 percentage points (95\% Cl=18.9-31.7) in 2011. Contraceptive use was more than twice (RII: $2.6,95 \% \mathrm{Cl}=2.0-3.3$ ) as prevalent among the richest compared with the poorest.

Conclusion: Despite efforts to provide contraceptives for free at all public health facilities, wealth based inequalities still prevail in Ethiopia. People at lower socioeconomic strata should be empowered more to avoid the root causes of inequality and to achieve national Health Sector Development Program Goals.

\section{Introduction}

The causes of health outcomes are very complex and highly dictated by social determinants of health. Those at lower social strata are with the worst health outcomes [1], exacerbated by lower coverage of basic health and social services.

Since its endorsment in 2005 by the World Health Assembly, a growing number of countries are showing a comitment to address the bottle necks of universal access and Universal Health Coverage (UHC). Neverthless, given increased resource constraints and service complexity, the poorer countries need to focus on priority services and gradually expand to less priority services

\footnotetext{
* Correspondence: yigzawm@gmail.com

${ }^{1}$ Ethiopian Public Health Associetion, Addis Ababa, Ethiopia

Full list of author information is available at the end of the article
}

instead of advancing all costly services at one point in time [2]. Family planning is one of the priority and highly cost effective services in least developed nations with significant impact on population health and economic development $[3,4]$.

Family planning plays a significant role to reduce maternal and child mortality and ultimatlely to achieve national and international development goals including the Millennium Development Goals (MDGs), formulated in 2000 but expiring this year 2015. By reducing high-risk and unwanted pregnancies, family planning can significantly reduce the risk of maternal and child deaths [5-8]. Children born with short birth intervals or from a teenage mother are more likely to be stunted or underweight in later life $[9,10]$. Conversely, malnutrition 
is closely linked to the major causes of under-five deaths in the developing world [11].

Apart from its effect on maternal and child mortality and morbidity, contraceptives have played a pivotal role in reducing new pediatrics HIV infections [12]. The World Health Organization (WHO) has identified family planning as one of the strategies for the prevention of motherto-child transmission (PMTCT) of HIV [13]. It is proven that voluntary contraceptive use prevents many infants from HIV infections as compared to common interventions of treating the mother and the infant with antiretroviral therapy [14-17]. Moreover, family planning as an HIV prevention approach is cost effective compared with other PMTCT approaches [14].

Investing in family planning is one of the smart investments for development as population dynamics have a fundamental influence on the pillars of sustainable development [18]. It is a balance and check for economic development and overall population growth and increases the capability of developing countries to provide all citizens with the required services including priority health services and adequate education. If high fertility rates continue to flourish among the poor, poverty will create a vicious circle as poor women and their families lose the opportunity to move successfully through education and into productive employment among others, including contributing to a more sustainable environment and reductions in pollution of all forms.

The last decade has witnessed a wide spread increase in the number of women wanting to avoid pregnancy and thus needing effective contraception in the developing world. However, the contraceptive prevalence rate remains unacceptably low in the majority of these nations [19] with a wide gap between the poor and the better off [20-22]. There were some 222 million women in developing countries wanting to plan their births but without having access to contraception in 2012 [23]. Despite the international consensus that access to safe and effective methods of contraception is a fundamental human right [24], women from poorest wealth quintiles have less likely to meet their needs for modern family planning methods $[21,22]$. The unmet need for modern contraception is as high as 60 \% in Sub-Saharan Africa, ranging from $81 \%$ in Middle Africa to $17 \%$ in Southern Africa [23].

Ethiopia showed substantial increase in the use of contraceptives in the last decade through a significant effort to scale up family planning services. The contraceptive prevalence rate increased from $8 \%$ in 2000 to $28.6 \%$ in 2011 among married women of reproductive age $[25,26]$. However, about $26 \%$ of women have not yet taken any type of contraceptive despite their demand. This high unmet need in contraceptives is probably because of a series of socio economic factors that affect the use of a range of health services including contraceptives.
The purpose of this study, therefore, was to identify and quantify wealth related differences in family planning use between poor and rich Ethiopian women based on the Demographic and Health Survey (DHS) asset based wealth quintiles. Furthermore we wanted to determine whether supplying contraceptives for free could address wealth related inequalities and to show that the national family planning coverage gap is a result of wealth related differences in family planning use and need satisfied.

\section{Methods}

\section{Data sources}

The authors analyzed the data of the 2011 Ethiopian Demographic and Health Survey (EDHS) and to some extent those of the 2005 EDHS to examine trends of inequality over five years. The study population was women of the reproductive age (15-49 years). Women were asked to respond to a series of questions related to their sociodemographic characteristics, reproductive behavior, use of maternal health services and the need for contraception. The detailed sampling procedure for the survey has been reported elsewhere [25].

\section{Variables}

To measure wealth related inequality in family planning use, two outcome variables were used:

- Current contraceptive use: Extracted from the question "Are you currently doing something or using any method to delay or avoid getting pregnant?" The answer was dichotomized into: 'Yes' and 'No'. When a woman also used a traditional method, she was put into the first category.

- Contraceptive needs satisfied: This is only for women who do not want to become pregnant and using contraception to avoid pregnancy. It is generated from the response to a number of questions in the women's questionnaire.

The main independent variable analyzed in this study was the wealth index. It is a composite measure of a household's cumulative living standard (economic position). Information on the wealth index is based on data collected in the household questionnaire; including questions related to: the household's ownership of consumer items; dwelling characteristics; drinking water sources; toilet facilities; and other characteristics such as number of people per room, bank account ownership, domestic servant in household, and ownership of agricultural land.

Wealth scores were much higher for urban women compared to rural women and resulted in more women in the richest quintile in urban areas and many more women in the poorest quintile in rural areas. To avoid this and to compare inequalities in contraceptive use 
and needs satisfied separately for rural and urban women, we used the national-level wealth scores as they were generated, and then divided each into quintiles separately in urban and rural areas. The detail methodology for wealth indexing is indicated elsewhere [27].

\section{Data analysis}

Univariate and multivariate statistical analyses were employed to analyze the data. Contraceptive prevalence rate and contraceptive needs satisfied were analyzed across wealth quintiles in a weighted sample of 10287 and 9066 women from the 2011 and 2005 EDHS respectively. Wealth related inequalities were measured using the absolute index of inequality (SII) and the relative index of inequality (RII). This was mainly to measure and compare changes in absolute and relative wealth related inequalities over the five years between the two surveys [28-30]. Additionally, population attributable risk (PAR) and the population attributable risk percentage was used to quantify the contribution of wealth based inequalities to the national coverage gaps [31,32].

To calculate SII and RII, individuals were cumulatively ranked according to ascending economic status. The exposure variable can thus be interpreted as a continuous measure, with a value of zero equivalent to the bottom economic distribution and a value of one equivalent to the top. SII was thus the prevalence rate difference and RII was the prevalence rate ratio between the highest and the lowest level of wealth.

Adjusted population attributable risks and attributable fractions were calculated to determine coverage gaps due to wealth. STATA's Margins command was used to calculate population attributable risk and population attributable risk percent.

Data were adjusted for educational status of women, as well as other confounding factors, including: age of women; place of residence; number of living children; working status; and husband's desire for more children. Both crude and adjusted results were presented. All the analyses were carried out using STATA $^{\circ}$ 12(STATA Corp. Texas, USA).

\section{Results}

A total of 10287 weighted number of married women from EDHS 2011 and 9066 women from DHS 2005 was included for the analysis. The mean age of the study participants was 30.7 ranging from 15 to 49 years. Study participants background characteristics are presented in Table 1.

Table 2 shows the average coverage, SII and RII in contraceptive use and needs satisfied among Ethiopian women. The 2011 EDHS showed that the contraceptive prevalence rate $(\mathrm{CPR})$ ranged from $51.8 \%$ among the richest to $13.3 \%$ among the poorest and the difference
Table 1 Frequency distribution of married women according to background characteristics, Ethiopia Demographic and Health survey (EDHS 2005 and 2011)

\begin{tabular}{|c|c|c|}
\hline \multirow[t]{2}{*}{ Variables } & 2011 & 2005 \\
\hline & $\mathrm{N}(\%)$ & N (\%) \\
\hline \multicolumn{3}{|l|}{ Age } \\
\hline $15-18$ & $528(5.1)$ & $533(5.9)$ \\
\hline $19-25$ & $2768(26.9)$ & $2492(27.5)$ \\
\hline $26-35$ & 4088 (39.7) & $3449(38.1)$ \\
\hline $36-49$ & $2903(28.2)$ & $2592(28.6)$ \\
\hline Total & 10287 & 9066 \\
\hline \multicolumn{3}{|l|}{ Place of residence } \\
\hline Urban & $1843(17.92)$ & 959 (10.6) \\
\hline Rural & 8444 (82.08) & $8107(89.4)$ \\
\hline Total & 10287 & 9066 \\
\hline \multicolumn{3}{|l|}{ Religion } \\
\hline Ethiopian Orthodox & $4490(43.69)$ & $4132(46.1)$ \\
\hline Muslim & 3187 (31.01) & $2903(32.4)$ \\
\hline Protestant & $2432(23.66)$ & $1804(20.1)$ \\
\hline Traditional & $169(1.64)$ & $134(1.5)$ \\
\hline Total & 10287 & 8973 \\
\hline
\end{tabular}

Educational Level

$\begin{array}{lll}\text { No education } & 6735(65.47) & 7094(78.2)\end{array}$

Primary $2862(27.82) \quad 1402(15.5)$

Secondary $\quad 377(3.67) \quad 485(5.4)$

$\begin{array}{lll}\text { Higher } & 312.8(3.04) & 85(0.9)\end{array}$

$\begin{array}{lll}\text { Total } & 10287 & 9066\end{array}$

Wealth index

$\begin{array}{lll}\text { Q1 } & 2077(20.19) & 1759(19.4) \\ \text { Q2 } & 2117(20.58) & 1892(20.9) \\ \text { Q3 } & 2083(20.25) & 1903(21.0) \\ \text { Q4 } & 1923(18.69) & 1823(20.1) \\ \text { Q5 } & 20287(20.29) & 1689(18.6) \\ \text { Total } & 10287 & 9066 \\ \text { Number of living children } & & \\ \text { No living children } & 1018(9.9) & 800(8.8) \\ \text { 1-2 living children } & 3193(31.0) & 2628(29.0) \\ \geq 3 & 6076(59.1) & 5638(62.2) \\ \text { Total } & 10287 & 9066\end{array}$

Number of people in the household

$\begin{array}{lll}\leq 4 & 3337(32.4) & 2681(29.6) \\ 5-7 \text { people } & 4910(47.7) & 4470(49.3) \\ \geq 8 & 2040(19.8) & 1915(21.1) \\ \text { Total } & 10287 & 9066 \\ \text { Respondent currently working } & & \\ \text { Yes } & 3678(35.8) & 2244(24.7) \\ \text { No } & 6600(64.2) & 6822(75.3)\end{array}$


Table 1 Frequency distribution of married women according to background characteristics, Ethiopia Demographic and Health survey (EDHS 2005 and 2011) (Continued)

\begin{tabular}{lll}
\hline $\begin{array}{l}\text { Total } \\
\text { Husband's desire for more children }\end{array}$ & 10277 & \\
Husband wants more & $2504(24.5)$ & $1540(17.1)$ \\
Wants same & $4234(41.4)$ & $2981(33.0)$ \\
Wants fewer & $887(8.7)$ & $433(4.8)$ \\
Unknown & $2598(25.41)$ & $4077(45.2)$ \\
Total & 10223 & 9031 \\
Contraceptive needs satisfied & & \\
Yes & $2944(52.11)$ & $1334(29.0)$ \\
No & $2705(47.9)$ & $3272(71.0)$ \\
Total & 5949 & 4606 \\
Contraceptive use & & $1334(14.7)$ \\
Yes & $2944(28.61)$ & $7732(85.3)$ \\
No & $7344(71.39)$ & 9066 \\
\hline Total & 10288 & \\
\hline
\end{tabular}

was significant $(p<0.001)$. Contraceptive usage between the poorest and the richest women differed by 25 percentage points in favor of the richest and, the contraceptive prevalence rate among the richest was more than two fold higher than the poorest. The national contraceptive needs satisfied were as high as 77 and $29 \%$ among women from richest and poorest households, respectively. There was a significant difference in the contraceptive needs satisfied between richest and poorest women with the richest being 30 percentage points higher than the poorest.
Table 3 shows the average contraceptive coverage, and SII and RII for women living in rural areas. Thirteen percent of rural women in the poorest quintile and $35.7 \%$ of women in the wealthiest quintile were using either modern or traditional methods of contraception in 2011.

About $33 \%$ and $52 \%$ of women from poorest and richest households in urban areas, respectively, were using contraceptives in 2011. Fifty-five percent of the poorest and $81.6 \%$ of the richest quintiles had contraceptive needs satisfied $(\mathrm{SII}=25.6$ percentage points, RII = 1.4) (Table 4). Significant difference was also observed in rural women with a lower absolute difference and a slight higher relative inequality ( $\mathrm{SII}=23.6$ percentage points, RII =1.7) (Table 3 ). The contraceptives needs satisfied followed a linear pattern of inequality among rural women while a bottom inequality pattern was observed in urban women with a coverage level of greater than $80 \%$ among those women in the middle, richer and richest wealth quintiles.

The contraceptive needs satisfied among poorest rural women increased from $9 \%$ in 2005 to $30 \%$ in 2011. Moreover, the adjusted rate ratio for contraceptive needs satisfied among women living in rural Ethiopia dropped from 3.7 in 2005 to 1.7 in 2011 (Table 3). However, as the intervention coverage increases, the absolute inequality in the contraceptive needs satisfied between the poor and the better off was not significantly changed both in urban and rural areas between 2005 and 2011. The contraceptive prevalence rate ratio among rural women dropped from 4.8 to 2.3. But the rate difference increased from 16 percentage points in 2005 to 19 percentage points in 2011 (Table 3). For

Table 2 Average prevalence/coverage, absolute and relative wealth related inequalities in family planning use and contraceptive needs satisfied among Ethiopian women, Ethiopia 2005 and 2011

\begin{tabular}{|c|c|c|c|c|c|c|c|c|c|c|}
\hline \multicolumn{6}{|c|}{ EDHS 2011} & \multicolumn{5}{|c|}{ EDHS 2005} \\
\hline Variable & $\%$ & $\begin{array}{l}\text { Crude SII } \\
(95 \% \text { Cl) }\end{array}$ & $\begin{array}{l}\text { Adj SII } \\
(95 \% \mathrm{Cl})\end{array}$ & $\begin{array}{l}\text { Crude RII } \\
(95 \% \text { Cl) }\end{array}$ & $\begin{array}{l}\text { Adj RII } \\
(95 \% \mathrm{Cl})\end{array}$ & $\%$ & $\begin{array}{l}\text { Crude SII } \\
(95 \% \text { Cl) }\end{array}$ & $\begin{array}{l}\text { Adj SII } \\
(95 \% \text { Cl) }\end{array}$ & $\begin{array}{l}\text { Crude RII } \\
(95 \% \text { Cl) }\end{array}$ & $\begin{array}{l}\text { Adj RII } \\
(95 \% \text { Cl) }\end{array}$ \\
\hline \multicolumn{11}{|c|}{ Contraceptive needs satisfied } \\
\hline Q1 & 29.5 & & & & & 10.4 & & & & \\
\hline Q2 & 44.6 & & & & & 14.5 & & & & \\
\hline Q3 & 45.6 & 51.5 & 30.3 & 3.11 & 1.85 & 23.5 & 54.6 & 31.9 & 10.38 & 3.40 \\
\hline Q4 & 53.0 & $(44.6-58.5)$ & $(20.8-39.9)$ & $(2.5-3.9)$ & $(1.5-2.3)$ & 28.3 & $(49.2-60.1)$ & $(24.0-39.7)$ & $(7.1-15.1)$ & $(2.4-4.8)$ \\
\hline Q5 & 77.5 & & & & & 58.5 & & & & \\
\hline \multicolumn{11}{|c|}{ Contraceptive use } \\
\hline Q1 & 13.3 & & & & & 4.2 & & & & \\
\hline Q2 & 22.2 & & & & & 6.6 & & & & \\
\hline Q3 & 24.4 & 42.6 & 25.3 & 4.96 & 2.55 & 12.0 & 38.7 & 21.7 & 17.00 & 5.13 \\
\hline Q4 & 31.7 & $(37.6-47.5)$ & $(18.9-31.7)$ & $(3.9-6.3)$ & $(2.0-3.3)$ & 15.5 & $(34.8-42.6)$ & $(16.9-26.4)$ & $(11.7-24.6)$ & $(3.5-7.5)$ \\
\hline Q5 & 51.8 & & & & & 37.0 & & & & \\
\hline
\end{tabular}


Table 3 Average prevalence/coverage, absolute and relative wealth related inequalities in family planning use and contraceptive needs satisfied among rural women, Ethiopia 2005 and 2011

\begin{tabular}{|c|c|c|c|c|c|c|c|c|c|c|}
\hline \multicolumn{6}{|c|}{ EDHS 2011} & \multicolumn{5}{|c|}{ EDHS 2005} \\
\hline Variable & $\%$ & Crude SII & Adj SII & Crude RII & Adj RII & $\%$ & Crude SII & Adj SII & Crude RII & Adj RII \\
\hline & & $(95 \%$ Cl) & $(95 \% \mathrm{Cl})$ & $(95 \% \mathrm{Cl})$ & $(95 \% \mathrm{Cl})$ & & $(95 \% \mathrm{Cl})$ & $(95 \% \mathrm{Cl})$ & $(95 \% \mathrm{Cl})$ & $(95 \% \mathrm{Cl})$ \\
\hline \multicolumn{11}{|c|}{ Contraceptive needs satisfied } \\
\hline Q1 & 30.1 & & & & & 9.4 & & & & \\
\hline Q2 & 39.5 & & & & & 13.6 & & & & \\
\hline Q3 & 43.3 & 32.0 & 23.6 & 2.1 & 1.7 & 21.1 & 32.3 & 26.5 & 5.0 & 3.7 \\
\hline Q4 & 49.1 & $(22.9-41.0)$ & $(14.5-32.7)$ & $(1.7-2.7)$ & $(1.4-2.2)$ & 26.8 & $(25.9-38.7)$ & $(20.1-32.0)$ & $(3.5-7.1)$ & $(2.6-5.2)$ \\
\hline Q5 & 57.7 & & & & & 35.3 & & & & \\
\hline \multicolumn{11}{|c|}{ Contraceptive use } \\
\hline Q1 & 13.3 & & & & & 3.7 & & & & \\
\hline Q2 & 19.1 & & & & & 6.1 & & & & \\
\hline Q3 & 23.0 & 25.8 & 18.6 & 3.1 & 2.3 & 10.8 & 21.0 & 16.2 & 7.3 & 4.8 \\
\hline Q4 & 25.9 & $(20.0-31.5)$ & $(12.9-24.3)$ & $(2.4-4.1)$ & $(1.8-2.9)$ & 14.3 & $(16.9-25.2)$ & $(12.4-19.9)$ & $(5.0-10.6)$ & $(3.4-6.8)$ \\
\hline Q5 & 35.7 & & & & & 19.9 & & & & \\
\hline
\end{tabular}

urban Ethiopia, neither the absolute nor the relative inequality showed a significant change (Table 4).

The national gap in the contraceptive needs satisfied was about $48 \%$ in 2011(Table 5). Wealth contributed about $53 \%$ of this coverage gap (PAR\%= 53.0, $95 \% \mathrm{CI}=44.0-60.6)$. In general, the coverage gap in the contraceptive needs satisfied was much lower in urban women than in rural women (23 vs 55). However, the population attributable risk did not significantly differ between urban and rural women (11.3 vs 12.2) (Table 5).

\section{Discussion}

Our study shows that despite a tremendous investment and an enormous increase in family planning use, significant disparity still exists between the poor and better off women in Ethiopia. Many studies conducted in the developing world have also showed that wealthier women are more likely to use family planning methods and maternal health care services than their less wealthy counterparts [33-35]. The relative inequality in family planning use and contraceptive needs satisfied between wealthiest and poorest women significantly dropped over five years period

Table 4 Average prevalence/coverage, absolute and relative wealth related inequalities in family planning use and contraceptive needs satisfied among urban women, Ethiopia 2005 and 2011

\begin{tabular}{|c|c|c|c|c|c|c|c|c|c|c|}
\hline \multicolumn{6}{|c|}{ EDHS 2011} & \multicolumn{5}{|c|}{ EDHS 2005} \\
\hline $\begin{array}{l}\text { Variable } \\
\end{array}$ & $\%$ & Crude SII & Adj SII & Crude RII & Adj Rll & $\%$ & Crude SII & Adj SII & Crude RII & Adj RII \\
\hline & & $(95 \% \mathrm{Cl})$ & $(95 \% \mathrm{Cl})$ & $(95 \% \mathrm{Cl})$ & $(95 \% \mathrm{Cl})$ & & $(95 \% \mathrm{Cl})$ & $(95 \% \mathrm{Cl})$ & $(95 \% \mathrm{Cl})$ & $(95 \% \mathrm{Cl})$ \\
\hline \multicolumn{11}{|c|}{ Contraceptive needs satisfied } \\
\hline Q1 & 55.0 & & & & & 46.4 & & & & \\
\hline Q2 & 75.9 & & & & & 66.8 & & & & \\
\hline Q3 & 82.9 & 31.9 & 25.6 & 1.5 & 1.4 & 75.8 & 36.9 & 24.1 & 1.7 & 1.4 \\
\hline Q4 & 87.4 & $(19.1-44.6)$ & $(10.3-40.9)$ & $(1.3-1.9)$ & $(1.1-1.8)$ & 81.5 & $(19.9-53.8)$ & $(6.2-42.1)$ & $(1.3-2.4)$ & $(1.1-1.9)$ \\
\hline Q5 & 81.6 & & & & & 77.3 & & & & \\
\hline \multicolumn{11}{|c|}{ Contraceptive use } \\
\hline Q1 & 33.4 & & & & & 27.1 & & & & \\
\hline Q2 & 53.4 & & & & & 47.6 & & & & \\
\hline Q3 & 60.1 & 23.7 & 22.5 & 1.6 & 1.6 & 51.8 & 28.0 & 20.0 & 1.8 & 1.6 \\
\hline Q4 & 63.1 & $(11.2-36.2)$ & $(9.1-35.9)$ & $(1.2-2.0)$ & $(1.2-2.0)$ & 55.8 & $(18.0-37.9)$ & $(8.7-31.3)$ & $(1.4-2.4)$ & $(1.2-2.0)$ \\
\hline Q5 & 52.4 & & & & & 51.2 & & & & \\
\hline
\end{tabular}


Table 5 Average gap in family planning use and contraceptive needs satisfied and within-country wealth based inequality in coverage gap, Ethiopia DHS 2011

\begin{tabular}{|c|c|c|c|c|}
\hline \multirow[t]{2}{*}{ Variable } & \multicolumn{2}{|c|}{ Coverage gap (95 \% Cl) } & \multirow{2}{*}{$\begin{array}{l}\text { PAR, percentage } \\
\text { points }(95 \% \mathrm{Cl})\end{array}$} & \multirow{2}{*}{$\begin{array}{l}\text { PAR \% } \\
(95 \% \mathrm{Cl})\end{array}$} \\
\hline & National & In richest quintile & & \\
\hline \multicolumn{5}{|l|}{ National } \\
\hline Contraceptive needs satisfied & $47.9(45.1-50.7)$ & $22.5(18.6-27.0)$ & $25.4(21.1-29.5)$ & $53.0(44.0-60.6)$ \\
\hline Contraceptive use & $71.4(69.4-73.3)$ & $48.2(44.3-52.2)$ & $23.2(19.3-26.9)$ & $32.4(27.0-(37.5)$ \\
\hline \multicolumn{5}{|l|}{ Rural } \\
\hline Contraceptive needs satisfied & $55.0(51.5-58.5)$ & $42.9(37.9-47.9)$ & $12.2(8.6-15.7)$ & $22.1(15.1-28.5)$ \\
\hline Contraceptive use & $76.6(74.2-78.8)$ & $65.4(61.5-69.2)$ & $11.2(8.5-13.8)$ & $14.6(10.9-18.1)$ \\
\hline \multicolumn{5}{|l|}{ Urban } \\
\hline Contraceptive needs satisfied & $34.1(19.1-(27.0)$ & $22.8(7.8-16.8)$ & $11.3(7.11-15.4)$ & $41.4(14.8-59.7)$ \\
\hline Contraceptive use & $47.5(44.0-51.1)$ & $38.0(32.1(44.3)$ & $9.5(4.4-14.5)$ & $20.0(8.5-30.0)$ \\
\hline
\end{tabular}

(between 2005 and 2011) in rural Ethiopia. However, such a trend was not observed among urban women. Significant change was also not observed in absolute wealth related inequality in both urban and rural areas. The coverage seems to have rapidly expanded to well-off groups leaving the worse off groups in urban areas unchecked which is regarded as an unacceptable trade off by the World Health Organization [2].

The Ethiopian Ministry of Health introduced the health extension program in 2002, deploying Health Extension Workers (HEWs) educated on 16 packages of health service including family planning in rural Ethiopia [36]. HEWs were working almost in all kebeles (the smallest administrative unit in Ethiopia, akin to an extended neighborhood) of the country in 2011 [37] during the time the 2011 EDHS was conducted. The contraceptive prevalence rate increased by almost three and half fold after introduction of the health extension program and the relative inequalities in family planning use between the poorest and wealthiest women also started to drop in rural Ethiopia in the period between 2005 and 2011. Nevertheless, the coverage for family planning among the poorest is thus far significantly lower than the coverage among the wealthiest groups and the absolute inequality has either worsened or not shown significant improvement.

On top of deploying HEWs to provide family planning and other essential services to the rural underserved populations, the ministry of health has supplied contraceptives free of charge at public health facilities. However, supplying contraceptives for free is only one step to achieve universal family planning coverage; poor quality services [38], frequent stock outs and other distal causes like legal and policy gaps can hinder family planning use especially among poor women. Wealthiest women may, for instance, use other service alternatives if the service quality deteriorates or if there are frequent stock outs at public facilities. The persistent wealth related gaps in family planning use and needs satisfied between 2005 and 2011 among urban women might be partly due to quality issues and stock outs at public facilities which leave the poor without access and alternatives as the private for profit facilities are unaffordable to them. Moreover, the poor usually have no voice in public decision-making, unless consulted through participatory methods, and are thereby excluded from a number of social and economic services.

Addressing the 'cause of causes', which is literally known as structural determinants, for family planning and other health service use requires systematic and well-designed investigations based on local contexts [39]. Structural reforms related to policy and legal frameworks might be crucial to reach all women in need of family planning and even important to create demand among those who have minimal appetite for family planning.

Though the health system most often focuses on the immediate causes of ill health and service coverage, it also must play a central role in addressing the 'cause of causes'. It needs to enable community participation $[40,41]$; inter-sectorial collaboration and most importantly, help shape societal norms and values [42, 43]. Participation of the poor during the planning, design and monitoring of health programs results in high service utilization and service coverage $[44,45]$. Inequality in family planning and other reproductive health services use is usually exacerbated if women are passive targets of health programs [46]. Full participation of the poor (including both women and men) at planning phase and during all stages of program implementation can give chance to family planning programmers to overcome bottlenecks to family planning use at all levels of facilities. It also boosts local resource mobilization and service sustainability. Re-defining and strengthening the primary health system is, therefore, crucial to address these problems of inequality.

Implementation research, too, can play a crucial role to make design changes to current strategies [47], to better 
reach the poor and to ensure that the health extension program has considered community participation as an important contributor in reaching all population groups regardless of their social position and in how to design effective and efficient strategies to increase the potential of community participation, which can so often be squandered [40].

Indirect costs might also be other obstacles for family planning utilization in rural areas where living depends on subsistence agriculture. Even though contraceptives are supplied free of charge to all women served at public health facilities, the poor may be excluded due to indirect costs such as opportunity losses and transportation costs to public facilities. Mobilizing local resources might fill this gap and facilitate service utilization by the poor for family planning and other priority services.

Gender inequality is more pronounced amongst poorest quintiles [48] clearly indicating that household assets are more likely to be controlled by men in the poorest households. Poorest women might not, therefore, get a green light to use contraceptives (or those of their choice) and hence be denied optimal family planning opportunities. Empowering those women at lower socioeconomic strata might, thus help to increase women's decision making power at household level and thereby decrease the gap in contraceptive use between the poor and the better off.

Wealth related inequality accounted for $53 \%$ (95\% $\mathrm{CI}=44.0-60.6 \%)$ of the coverage gap in the contraceptive needs satisfied in 2011; with the national coverage gap dropping to $22.5 \%$ if no wealth related inequality existed. Hosseinpoor et al. reported that wealth related inequality accounted for $51 \%$ of the coverage gap in Namibia, $47 \%$ in Madagascar and $20 \%$ in Chad based on demographic and health surveys conducted between 2000 and 2008 [33] which indicates that within country wealth related inequalities vary widely among countries as a cause of contraceptive use variation. However while within country inequalities differ among countries, its contribution to the national coverage gaps were significant in most SubSaharan Africa countries. It is, therefore, identified further as a major challenge in the effort to reach universal family planning coverage and must be seriously dealt with.

Our study has some limitations. First of all, we used cross-sectional data, which can only show associations rather than causal relationships between explanatory variables and the outcomes of interest, though two discrete points in time were used with the two DHSs. Second, wealth quintiles represent only relative wealth differences and the inequality observed in this study might be because of other forms of disparity (e.g. education). We, however, conducted multivariate and stratified analysis to control all these forms of disparities to come up with refined results. We analyzed, for instance, contraceptive use for rural and urban women separately to avoid disparities related to geographic access. Major variables considered as confounders such as education, age of women, place of residence, number of living children, working status and husband's desire for more children were included in the multivariate analysis model. However, we did not adjust for other factors that might influence contraceptive use among women but that were not part of the DHS (e.g. contraceptive stockouts, health system empathy, etc.). Thus, our findings need to be interpreted with caution, since women may have used or may have been excluded from family planning services for reasons not included in the regression equations.

\section{Conclusion}

Over all, the study result shows that wealth based inequalities in contraceptive use still prevail in Ethiopia despite the efforts to provide them for free at all public health facilities. Such existing wealth inequalities will, nonetheless, continue to pose a challenge to achieve national Health Sector Development Program targets and universal family planning coverage will not be realized. All actors in the arena have to understand that the cost of medical services is not the only reason for health disparity between the poor and the rich. Unless properly empowered to use the service, people at lower social stratum will be left behind and will be excluded from these (and other) priority services. The source of inequalities are deep rooted and multifactorial. The root causes of inequity and inequality should be systematically identified and targeted to make the services universal to all groups and achieve the national Health Sector Development Program goals. Apart from deep rooted structural causes, factors at the health system level should also be carefully scrutinized as quality of the service, hospitality factors and frequent stock outs might prevent the poor from using family planning services. Further qualitative and quantitative studies should also be carried out to find out the multi-level factors that exclude poorest women from family planning services apart from financial constraints, and to continue monitoring success in achieving universal health service goals.

\section{Abbreviations \\ UHC: Universal Health Coverage; MDGs: Millennium Development Goals; WHO: World Health Organization; PMTCT: Prevention of mother to child transmission of HIV; DHS: Demographic and Health Survey; EDHS: Ethiopia Demographic and Health Survey; RII: Relative index of inequality; SII: Slop index of inequality; CPR: Contraceptive prevalence rate; PAR: Population attributable risk; HEW: Heath extension worker.}

\section{Competing interest}

The authors have no conflicts of interest.

\section{Authors' contributions}

MY developed the analysis plan. YT and MY coordinated and conducted the analysis. MY drafted the manuscript with revisions by DZ. All authors reviewed and approved the final manuscript writing. 


\section{Acknowledgment}

We would like to thank Central Statistical Agency of Ethiopia and ICF International for making the DHS dataset available for further analysis. "Like slavery and apartheid, poverty is not natural. It is man-made and it can be overcome and eradicated by the actions of human beings. And overcoming poverty is not a gesture of charity. It is an act of justice. It is the protection of a fundamental human right, the right to dignity and decent life. While poverty persists, there is no true freedom."

Nelson Mandela (1918-2013)

\section{Author details}

'Ethiopian Public Health Associetion, Addis Ababa, Ethiopia. ${ }^{2}$ Faculty of Community Services, School of Occupational and Public Health, Ryerson University, Toronto, Canada. ${ }^{3}$ Columbia University - ICAP in Ethiopia, Addis Ababa, Ethiopia. ${ }^{4}$ Amref Health Africa in Ethiopia, Addis Ababa, Ethiopia. ${ }^{5}$ School of Public Health, Addis Ababa University, Addis Ababa, Ethiopia.

Received: 15 April 2015 Accepted: 9 September 2015 Published online: 14 September 2015

\section{References}

1. Commission on Social Determinants of Health. Achieving health equity: from root causes to fair outcomes. Geneva, Switzerland: World Health Organization; 2007.

2. World Health Organization. Making fair choices on the path to universal health coverage, Final report of the WHO Consultative Group on Equity and Universal Health Coverage. Geneva, Switzerland: World Health Organization; 2014.

3. Osotimehin B. Family planning save lives, yet investments falter. Lancet. 2012;380:82-3.

4. Van Braeckel D, Temmerman M, Roelens K, Degomme O. Slowing population growth for wellbeing and development. Lancet. 2012;380:84-5.

5. Marston C, Cleland JG. The effects of contraception on obstetric outcomes. Geneva: World Health organization; 2004.

6. Prata N, Sreenivas A, Vahidnia F, Potts M. Saving maternal lives in resource-poor settings: facing reality. Health Policy. 2009:89:131-48.

7. Conde-Agudelo A, Rosas-Bermudez A, Kafury-Goeta AC. Effects of birth spacing on maternal health: a systematic review. Am J Obstet Gynecol. 2007;196:297-308.

8. Bongaarts J, Westoff CF. The potential role of contraception in reducing abortion. Stud Fam Plann. 2000;31:193-202.

9. Gribble JN, Murray NJ, Menotti EP. Reconsidering childhood undernutrition: can birth spacing make a difference? An analysis of the 2002-2003 El Salvador National Family Health Survey. Matern Child Nutr. 2009;5:49-63.

10. Fink G, Sudfeld CR, Danaei G, Ezzati M, Fawzi WW. Scaling-up access to family planning may improve linear growth and child development in low and middle income countries. PLoS One. 2014;9:e102391.

11. World Health Organization. Essential Nutrition Actions: Improving Maternal, Newborn, Infant and Young Child Health and Nutrition. Geneva: World Health Organization; 2013.

12. Cohen S. Hiding in plain sight: the role of contraception in preventing HIV. Guttmacher Policy Review. 2008; 11:2-5.

13. World Health Organization. Strategic approaches to the prevention of HIV infection in infants: report of a WHO meeting, Morges, Switzerland, 20-22 March 2002 [http://www.who.int/hiv/pub/mtct/strategic/en/ index.html]. Accessed on 30 March 2015.

14. Reynolds HW, Janowitz B, Wilcher R, Cates W. Contraception to prevent HIV-positive births: current contribution and potential cost savings in PEPFAR countries. Sex Transm Infect. 2008;84 Suppl 2:ii49-53.

15. Reynolds HW, Steiner MJ, Cates Jr W. Contraception's proved potential to fight HIV. Sex Transm Infect. 2005;81:184-5.

16. Babones SJ. Income inequality and population health: correlation and causality. Soc Sci Med. 2008;66:1614-26.

17. Hladik W, Stover J, Esiru G, Harper M, Tappero J. The contribution of family planning towards the prevention of vertical HIV transmission in Uganda. PLoS One. 2009;4:e7691.

18. Habumuremyi PD, Zenawi M. Making family planning a national development priority. Lancet. 2012;380:78-80.

19. Tsui AO, McDonald-Mosley R, Burke AE. Family planning and the burden of unintended pregnancies. Epidemiol Rev. 2010;32:152-74.

20. Gakidou E, Vayena E. Use of modern contraception by the poor is falling behind. PLoS Med. 2007;4:e31.
21. Gillespie D, Ahmed S, Tsui A, Radloff S. Unwanted fertility among the poor: an inequity? Bull World Health Organ. 2007;85:100-7.

22. Creanga AA, Gillespie D, Karklins S, Tsui AO. Low use of contraception among poor women in Africa: an equity issue. Bull World Health Organ. 2011;89:258-66.

23. Darroch JE, Singh S. Trends in contraceptive need and use in developing countries in 2003, 2008, and 2012: an analysis of national surveys. Lancet. 2013;381:1756-62.

24. Bloom D, Canning D. Population, poverty reduction, and the Cairo Agenda In: Proceedings of the Seminar on the Relevance of Population Aspects on the Achievement of the Millennium Development Goals. New York, United States of America: United Nations Population Fund (UNFPA); 2004.

25. Central Statistical Agency [Ethiopia] and ICF International: Ethiopia Demographic and Health Survey 2011. Addis Ababa: Central Statistical Agency; 2012.

26. Central Statistical Agency [Ethiopia] and ORC Macro: Ethiopia Demographic and Health Survey 2005. Addis Ababa: Central Statistical Agency; 2006.

27. Rutstein SOKJ. The DHS Wealth Index. DHS Comparative Reports No. 6. Calverton, Maryland: ORC Macro; 2004.

28. Barros AJ, Victora CG. Measuring coverage in $\mathrm{MNCH}$ : determining and interpreting inequalities in coverage of maternal, newborn, and child health interventions. PLoS Med. 2013;10:e1001390.

29. Houweling TA, Kunst AE, Huisman M, Mackenbach JP. Using relative and absolute measures for monitoring health inequalities: experiences from crossnational analyses on maternal and child health. Int J Equity Health. 2007;6:15.

30. Moser K, Frost C, Leon DA. Comparing health inequalities across time and place-rate ratios and rate differences lead to different conclusions: analysis of cross-sectional data from 22 countries 1991-2001. Int J Epidemiol. 2007;36:1285-91.

31. Mackenbach JP, Kunst AE. Measuring the magnitude of socio-economic inequalities in health: an overview of available measures illustrated with two examples from Europe. Soc Sci Med. 1997;44:757-71.

32. World Health Organization. Handbook on health inequality monitoring: with a special focus on low- and middle-income countries. Geneva, Switzerland: World Health Organization; 2013.

33. Hosseinpoor AR, Victora CG, Bergen N, Barros AJ, Boerma T. Towards universal health coverage: the role of within-country wealth-related inequality in 28 countries in sub-Saharan Africa. Bull World Health Organ. 2011;89:881-90.

34. Barros AJ, Ronsmans C, Axelson H, Loaiza E, Bertoldi AD, Franca GV, et al. Equity in maternal, newborn, and child health interventions in Countdown to 2015: a retrospective review of survey data from 54 countries. Lancet. 2012;379:1225-33.

35. Boerma JT, Bryce J, Kinfu Y, Axelson H, Victora CG. Mind the gap: equity and trends in coverage of maternal, newborn, and child health services in 54 Countdown countries. Lancet. 2008:371:1259-67.

36. Federal Ministry of Health. Health Sector Development II. Addis Ababa: Federal Ministry of Health; 2002

37. Federal Ministry of Health. Health Sector Development Program IV. Addis Ababa: Federal Ministry of Health; 2010.

38. Universal health coverage post-2015: putting people first. Lancet 2014, 384:2083.

39. Ward PR, Meyer SB, Verity F, Gill TK, Luong TC. Complex problems require complex solutions: the utility of social quality theory for addressing the Social Determinants of Health. BMC Public Health. 2011;11:630.

40. Zakus JD. Resource dependency and community participation in primary health care. Soc Sci Med. 1998;46:475-94.

41. Zakus JD, Lysack CL. Revisiting community participation. Health Policy Plan 1998;13:1-12.

42. Gilson L. Trust and the development of health care as a social institution Soc Sci Med. 2003;56:1453-68.

43. Daher M. Overview of the World Health Report 2000 Health systems: improving performance. J Med Liban. 2001;49:22-4.

44. Rifkin SB. A framework linking community empowerment and health equity: it is a matter of CHOICE. J Health Popul Nutr. 2003;21:168-80.

45. Del Castello, R; Braun, P.M. Lessons learned. Use of participatory methods for active involvement of all partners in communication [http://www.fao.org/Participation/ participatory-communication-lesson.html]. Accessed on 30 March 2015.

46. Yamin AE. Applying human rights to maternal health: UN Technical Guidance on rights-based approaches. Int J Gynaecol Obstet. 2013;121:190-3.

47. World Health Organization. World health report 2013: Research for universal health coverage. Geneva, Switzerland: WHO; 2013.

48. Dibaba Y. Women's Autonomy and Reproductive Healthcare-Seeking Behavior in Ethiopia. ICF International: Calverton, Maryland, USA; 2013. 